\title{
Overall fuzzy logic control strategy of direct driven PMSG wind turbine connected to grid
}

\author{
Mhamed Fannakh, Mohamed Larbi Elhafyani, Smail Zouggar, Hassan Zahboune \\ Laboratory of Electrical Engineering and Maintenance (LEEM), University Mohammed 1st, High School of Technology, \\ Oujda, Morocco
}

\begin{tabular}{l} 
Article Info \\
\hline Article history: \\
Received Sep 13, 2020 \\
Revised Mar 4, 2021 \\
Accepted Apr 29, 2021 \\
\hline
\end{tabular}

Keywords:

Anti-windup compensation Fuzzy logic control Grid connection MPPT

PMSG

Wind energy

\begin{abstract}
The fuzzy logic strategies reported in the literature about the control of direct drive permanent magnet synchronous generator (PMSG) connected to grid are limited in terms of inclusiveness and efficiency. So an overall control based on fuzzy logic and anti-windup compensation is proposed in this paper. Aiming at the inadequate of hill climb search (HCS) MPPT with fixed step size, the fuzzy logic is introduced in the stage of "generating rotor speed reference" to overcome the oscillations and slowness in traditional method. PI controllers are replaced by anti-windup fuzzy logic controllers in the "machine side control" stage and in "grid side control" stage to pertinently regulate the reference parameters. Then comparison tests with classical methods are implemented under varying climatic conditions. The results obtained demonstrate that the developed control is superior to other methods in response time (less than 4.528E-04 s), precision (an overshoot about $0.41 \%$ ) and quality of produced energy (efficiency is $91 \%$ ). The study verifying the feasibility and effectiveness of this algorithm in PMSG wind turbine connected to grid.
\end{abstract}

This is an open access article under the CC BY-SA license.

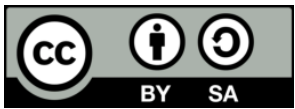

\section{Corresponding Author: \\ Mhamed Fannakh \\ Laboratory of Electrical Engineering and Maintenance (LEEM) \\ High School of Technology \\ University Mohammed 1st \\ PB 473 Al Quds University Complex, Oujda 60000, Morocco \\ Email: fannakh.mhamed@gmail.com}

\section{INTRODUCTION}

World energy consumption continues to grow, especially in underdeveloped countries. This growth requires increased energy production. World energy mix is based on fossil energies. These fossil resources are limited and can't track the consumption growth; this situation explains the rise in crude oil prices. As a result, renewable energy resources are becoming increasingly competitive. This is especially relevant for certain countries such as Morocco where the energy bill is expensive and where renewable resources such as wind and sun are often available locally [1]. The energy crisis is strongly linked to the environmental crisis. Indeed, the excessive consumption of fossil resources and the resulting greenhouse gases emission are the main cause of global warming. Wind energy is growing exponentially, this growth started before the lived energy crisis, but this crisis has fueled it in recent years. The technological development of wind turbines, the evolution of semiconductor technology and new control techniques are all linked to this growth.

Among different types of wind structures, the direct driven permanent magnet synchronous generator (PMSG), by its qualities of robustness, cost and simplicity seems well suited for use in wind power system connected to grid [2]. This machine improves system reliability and reduces maintenance costs by 
eliminating the gearbox. To increase the electrical energy competitiveness produced by PMSG wind turbines, it is necessary to reduce its cost and provide quality, secure and reliable energy. In regards to cost reduction, control laws must be designed to maximize the energy efficiency of PMSG wind turbines and avoid transmitting the wind fluctuations in the produced power [3]. It must also be robust in the face of grid disturbances and load variations. Finally, the control should contribute in the voltage and frequency regulation, by controlling the active and reactive power injected into grid.

Fuzzy logic control appears as a competitive solution to enhance the classical control and to ensure the required standards of electrical grid connection [4]. In the literature, many control strategies based on fuzzy logic [5]-[7] have been proposed to solve the problem that the traditional control methods cannot ensure. fuzzy logical control FLC was included in hill climbing search (HCS) method in [8]. The authors examine the added value provided by FLC in the search of the reference rotational speed which gives the maximum power point (MPP). Internal loop regulators of machine side control and grid side control are PI type. The linear regulators are well known to eliminate the static error. Though, their dynamic response is not convincing enough. an adaptive Fuzzy-PI speed controller is proposed to overcome the system nonlinearity [9]. The control of the stator currents is achieved using conventional PI controllers consequently non-linear control is not ensured for the whole system. Zaragoza et al. [10] proposed a control strategy based on Takagi-Sugeno FLC for tracking the rotor speed to achieve the MPPT. The study concluded that TakagiSugeno FLC is more stable under varying wind conditions. The rotational speed reference is calculated according to the operating optimal point for different wind speeds. However, a precise measurement for wind speed is necessary which increases the system cost. In the interest of regulating the direct and quadrature current components of PMSG, FLC Mamdani type controllers were proposed in [11]. The authors showed that the fuzzy logic is capable to improve the PMSG performance and attenuating the current fluctuations. Optimal torque control is used as MPPT algorithm due to its simplicity. However, its dependency on wind turbine characteristics made it unsuitable. Study [12] has replaced the conventional PI controllers by the fuzzy controllers to regulate the DC link voltage and the unity power factor of a grid-connected wind energy conversion system. The proposed method can reduce the DC link voltage fluctuation and provides a smooth output power to the grid. The main criterion in grid connection system is the total harmonics distortion (THD) that is not evaluated in this study.

Aiming at the reviewed works are limited in terms of performances and cost, an overall FLC of direct driven PMSG wind turbine connected to Grid is proposed in this work. Aiming at the reviewed works are limited in terms of performances and cost, an overall FLC of direct driven PMSG wind turbine connected to Grid is proposed in this work. At the same time, the standard PI controllers are replaced by new fuzzy logic controllers with anti-windup compensation. The main goals are to produce the maximum available power, attenuate the DC link voltage fluctuation and meet the requirements of grid connection.

\section{RESEARCH METHOD}

The proposed system configuration is shown in Figure 1. It includes a wind turbine, PMSG, PWM rectifier, capacitor filter, PWM inverter and utility grid. The wind turbine is directly coupled to the PMSG by the drive shaft. The three-phase IGBT rectifier with capacitor filter converts the AC generator voltages into DC voltage. The inverter assumes the connection function to the utility grid through a coupling resistor/inductor. A machine side control is used to track the maximum power point available regardless of the wind speed. Moreover, the grid side control is used to ensure the required standards of grid connection.

\subsection{Wind turbine model}

A wind turbine role is to transform the wind kinetic energy into mechanical energy. In the literature, two main theories are used to study and model the wind turbine aerodynamic behavior: the blade element theory and that of the actuator disk. Based on energy balances and the application of the Bernoulli equation, the wind turbine blades capture only a part of the power contained as kinetic energy in the wind [13]:

$$
P=\frac{1}{2} \rho \pi R^{2} V_{w}^{3} C_{p}(\lambda, \beta)
$$

where $\rho$ is the air density $\left(1.225 \mathrm{~kg} / \mathrm{m}^{3}\right), R$ is the blades radius (in $\mathrm{m}^{2}$ ), $V_{w}$ is the wind speed (in $\mathrm{m} / \mathrm{sec}$ ) and $C p$ is the power coefficient. It is a parameter (without unit) that expresses the efficiency of the wind turbine in the transformation of wind kinetic energy into mechanical energy. This coefficient is a non-linear function of the blades pitch angle $\beta$ and the tip speed ratio $\lambda$ between the rotor speed $\omega_{m}$ and the wind speed:

$$
\lambda=\frac{R \cdot \omega_{m}}{V_{w}}
$$


The small wind turbines are equipped with fixed blades which means that $\beta=0$. With this architecture, an aerodynamic stall is strongly recommended to degrade the turbine efficiency beyond a certain wind speed. In the literature, $C_{p}$ is expressed as a function of the coefficients $\lambda$ and $\beta$ [2].

$$
\left\{\begin{array}{c}
C_{p}(\lambda, \beta)=0.5176\left(\frac{116}{\gamma}-0.4 \beta-5\right) e^{\frac{-21}{\gamma}}+0.0068 \lambda \\
\frac{1}{\gamma}=\frac{1}{\lambda+0.08 \beta}-\frac{0.035}{\beta^{3}+1}
\end{array}\right.
$$

Since the turbine studied has a fixed pitch $(\beta=0)$, Therefore (3) becomes:

$$
C_{p}(\lambda)=0.5176\left(\left(\frac{1}{\lambda}-0.035\right) 116-5\right) e^{-21\left(\frac{1}{\lambda}-0.035\right)}+0.0068 \lambda
$$

The power coefficient $C p$ reaches its maximum of 0.48 when $\lambda=8.12$.

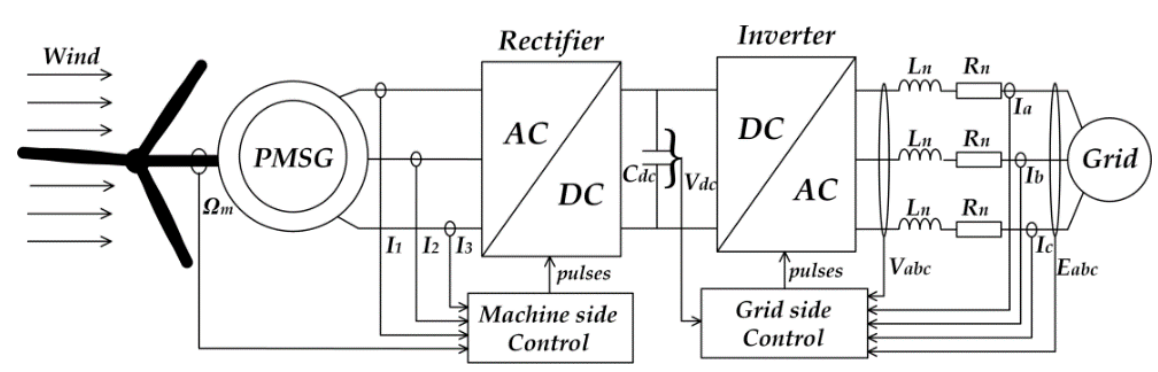

Figure 1. Bloc diagram of the studied system

\subsection{PMSG model on d-q coordinate system}

The PMSG comprises a three-phase windings system in its stator, $120^{\circ}$ phase-shifted relative to each other in the rotor, the permanent magnets provide the excitation. Depending on the permanent magnets position, two rotor types can be distinguished. In the first type, the permanent magnets are mounted on the rotor surface and providing a homogeneous air gap. The machine is called "PMSG with smooth rotor" and the inductors are independent of the rotor position. In the second type, the permanent magnets are mounted inside the rotor and the air gap will be variable due to the saliency effect. This machine is called "salientpole". In this case, the inductors depend strongly on the rotor position. The rotor diameter of the first type is smaller than that of the second which reduces considerably its inertia. In order to model the PMSG, the usual simplifying hypotheses listed in [14] are adopted. The PMSG mathematical model in park reference frame is given by system of (5):

$$
\left\{\begin{array}{c}
u_{s d}=R_{s} \cdot i_{s d}+L_{d} \cdot \frac{d i_{s d}}{d t}-\omega_{e} \cdot L_{q} \cdot i_{s q} \\
u_{s q}=R_{s} \cdot i_{s q}+L_{q} \cdot \frac{d i_{s q}}{d t}+\omega_{e} \cdot L_{d} i_{s d}+\omega_{e} \cdot \psi_{f}
\end{array}\right.
$$

where $u_{s d}$ and $u_{s q}$ are the $d$-axis and $q$-axis PMSG stator voltages (V), respectively; $i_{\text {sd }}$ and $i_{\text {sq }}$ are the $d$-axis and $q$-axis PMSG stator currents (A), respectively; $L_{d}$ and $L_{q}$ are the $d$-axis and $q$-axis PMSG inductances $\left(\mathrm{H}\right.$, respectively; $R_{s}$ is the stator winding resistance $(\Omega) ; \psi_{f}$ is the permanent magnetic flux $(\mathrm{Wb})$ and $\omega_{e}$ is the electric pulsation $(\mathrm{rad} / \mathrm{s})$.

In Laplace domain it can be expressed as system of (6):

$$
\left\{\begin{array}{c}
i_{s d}=\frac{1}{R_{s}+s \cdot L_{d}} \cdot\left(u_{s d}+\omega_{e} \cdot L_{q} \cdot i_{s q}\right) \\
i_{s q}=\frac{1}{R_{s}+s \cdot L_{q}} \cdot\left(u_{s q}-\omega_{e} \cdot L_{d} i_{s d}-\omega_{e} \cdot \psi_{f}\right)
\end{array}\right.
$$

The electromagnetic torque developed by the machine is written in park reference as (6):

$$
T_{e m}=\frac{3}{2} \cdot p\left(\left(L_{d}-L_{q}\right) \cdot i_{s d} \cdot i_{q s}+i_{s q} \cdot \psi_{f}\right)
$$

Overall fuzzy logic control strategy of direct driven PMSG wind turbine connected to... (Mhamed Fannakh) 
where $p$ is the pole pairs number.

For rigid wind turbines or when the representation of their flexibility is unnecessary, the mechanical module contains a simple rotating mass. The total equivalent inertia is the sum of wind turbine inertia and that of the generator. For the total equivalent friction the same theory is applied. The studied system is without gearbox which means that the wind turbine rotational speed is equal to the generator speed. The mechanical system dynamics is then described by a first order differential equation:

$$
J_{t} \frac{d \omega_{m}}{d t}=T_{t}-T_{e m}-f_{t} \omega_{m}
$$

where $J_{t}$ is the total equivalent inertia, $f_{t}$ is the total viscous friction coefficient and the $T_{t}$ is the mechanical torque. It can be expressed in Laplace domain by (9):

$$
\omega_{m}=\frac{1}{f_{t}+s . J_{t}}\left(T_{t}-T_{e m}\right)
$$

The block diagram of the electrical and mechanical model is presented in Figure 2. In order to control the power produced by the PMSG wind turbine and improve its quality, various converter topologies can be selected according to load types, system size and economic criteria [15]. IGBT-based buck-to-buck rectifier-inverter owns a flexible structure for different control methods and can be used to adjust the generator speed and control the power injected into a utility grid. PWM rectifier/inverter is made using the IGBT transistors as switchable semiconductors. These devices offer the advantages stated in [15]. Several control strategies have been proposed in recent works such as: Hysteresis PWM, Periodic sampling PWM, Sine-triangular PWM and space-vector modulation (SVM). Study [16] has compared these techniques and concluded that SVM technique is the most efficient.

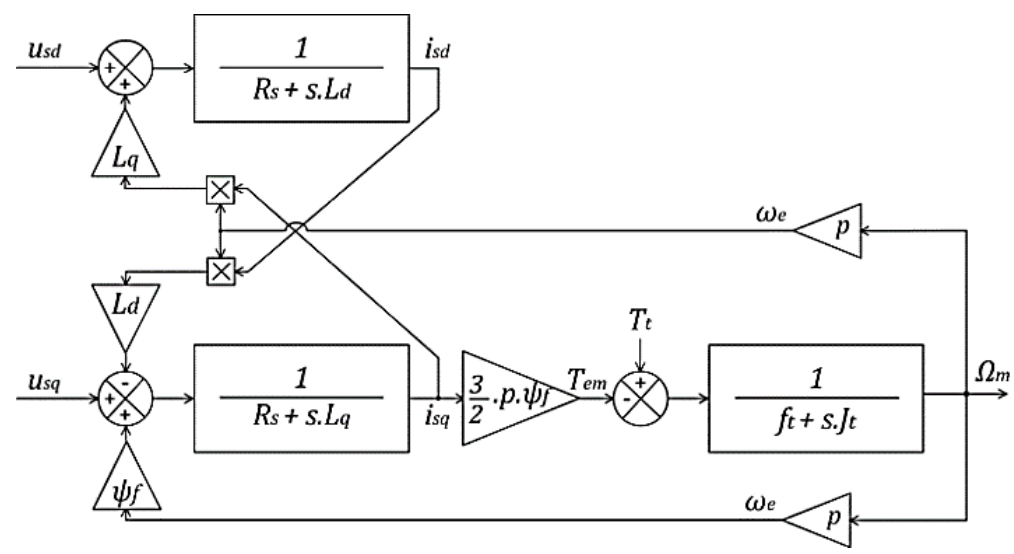

Figure 2. PMSG mathematical model

\subsection{The Grid-Connected wind turbine system modeling}

According to Figure 1, the mathematical model of wind turbine PMSG system connected to grid can be written as in (10):

$$
\left[\begin{array}{l}
V_{a}-e_{a} \\
V_{b}-e_{b} \\
V_{c}-e_{c}
\end{array}\right]=R_{n}\left[\begin{array}{c}
I_{a} \\
I_{b} \\
I_{c}
\end{array}\right]+L_{n} \frac{d}{d t}\left[\begin{array}{c}
I_{a} \\
I_{b} \\
I_{c}
\end{array}\right]
$$

where $e_{a}, e_{b}, e_{c}$ are the grid voltages, $V_{a}, V_{b}, V_{c}$ are the inverter output voltages, $I_{a}, I_{b}, I_{c}$ is the output currents of the inverter, $R_{n}$ is the coupling resistor and $L_{n}$ is the coupling inductance. The equation (10) is transformed from the three phases reference to the Park reference as (11):

$$
\left[\begin{array}{c}
V_{d}-e_{d} \\
V_{q}-e_{q} \\
0
\end{array}\right]=R_{n}\left[\begin{array}{c}
I_{d} \\
I_{q} \\
0
\end{array}\right]+L_{n} \frac{d}{d t}\left[\begin{array}{c}
I_{d} \\
I_{q} \\
0
\end{array}\right]+L_{n}\left[\begin{array}{c}
-\omega I_{q} \\
\omega I_{d} \\
0
\end{array}\right]
$$


The Laplace transformation of (11) is given by (12) and (13):

$$
\begin{aligned}
& I_{d}=\frac{1}{R_{n}+s L_{n}} \cdot\left(V_{d}-e_{d}+L_{n} \omega I_{q}\right) \\
& I_{q}=\frac{1}{R_{n}+s L_{n}} \cdot\left(V_{q}-e_{q}-L_{n} \omega I_{d}\right)
\end{aligned}
$$

where $e_{d}, e_{q}$ are the direct and the quadrature grid voltages, respectively, $I_{d}, I_{q}$ are the direct and the quadrature grid currents, respectively, $\omega=2 \pi f$ the pulsation and $f$ is the fundamental frequency of grid voltage $\mathrm{f}=50 \mathrm{~Hz}$ and $\mathrm{s}$ is the Laplace operator. To cure the problem of the coupling which exists between the directaxis and quadrature-axis currents, the decoupling method described in [17] is proceeded.

\subsection{Machine side control strategy}

A PMSG wind turbine is a generator with nonlinear characteristic (power/rotor speed). It's influenced by the wind speed variation. In Figure 3 the wind turbine is subject to wind speed variations where it appears clearly the change in maximum power point (MPP). For that reason, a controllable rectifier is inserted in the system energy chain. The rectifier control objective is to force the wind system to permanently produce its available maximum power. That is possible if the operating rotor speed is well chosen. As seen in Figure 3, for each wind speed, the turbine can only provide its MPP in a particular rotor speed. Therefore, the machine side control called MPPT aims firstly to find the optimal rotor speed and secondly drives the PMSG generator at this optimal speed by using regulation loops.

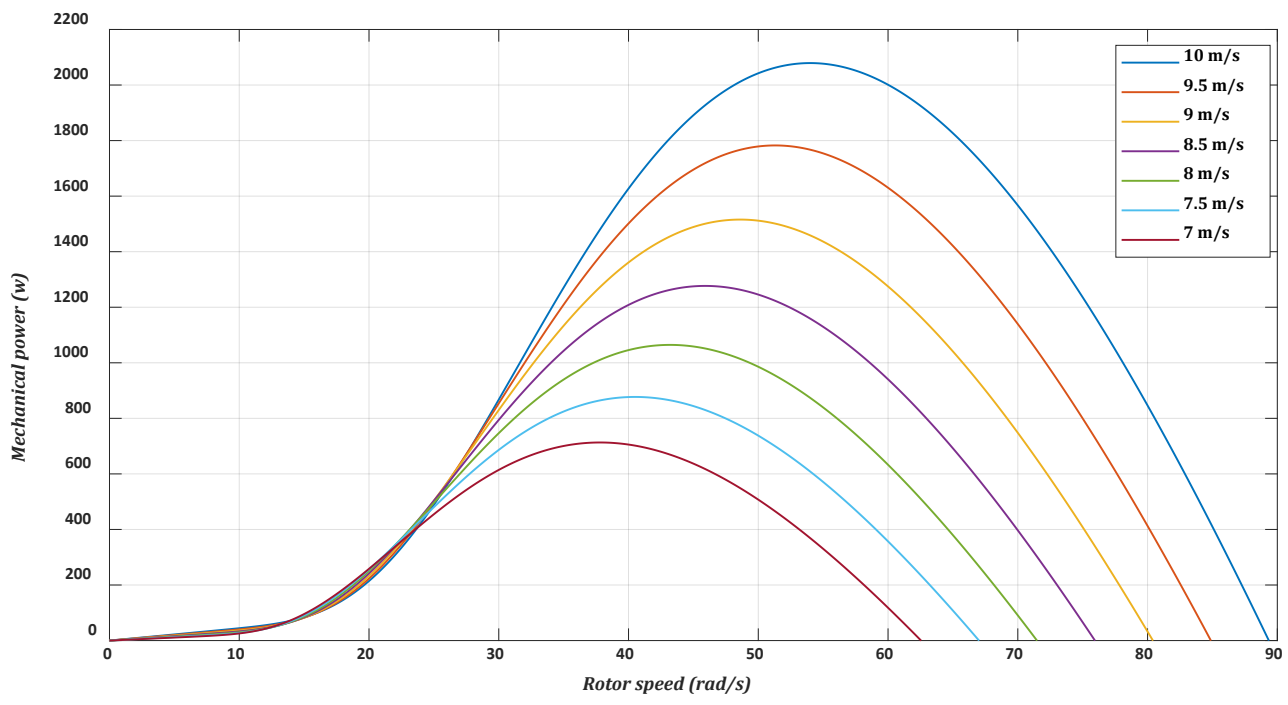

Figure 3. Wind turbine power characteristics

To drive the PMSG generator at speed reference, vector control similar to that of permanent magnet synchronous motor is used. Vector control amounts to controlling the direct-axis and quadrature-axis currents ( $i_{\text {sd }}$ and $i_{s q}$ ) by imposing the reference voltages $\mathrm{Vd}^{*}$ and $\mathrm{Vq}^{*}$ at the inverter input. The controllers used can be PI type, FLC, and sliding mode controller. The global configuration is schematized in Figure 4.

In the interest of reducing the system price, by eliminating the wind speed sensor, a wind-sensorless MPPT strategy based on the HCS technique [18] and fuzzy logic approach [19] as already proposed in our work [20]. As previously mentioned, the command objective is to force the generator to operate at an optimal speed. This requires the implementation of a cascading control strategy composed of speed control loop and that of internal currents. Firstly, PI regulators are proposed to achieve the control objective. Then the fuzzy logic for self-tuning the PI gains and the anti-windup compensator to prevent performance degradation are applied.

\subsubsection{Speed PI controller design}

The dynamics system is described by a first order equation given in (9), characterized by a single time constant. The insertion of the PI regulator will result in the functional diagram illustrated in Figure 5. It 
can be seeing that the speed regulator role is to determine the reference torque, in order to maintain the corresponding speed. The synthesis of the PI controller gains goes through "poles placement method" of the direct closed loop. The PI controller gains are quantified by using PID Tuner delivered by control system Toolbox of MATLAB/Simulink.

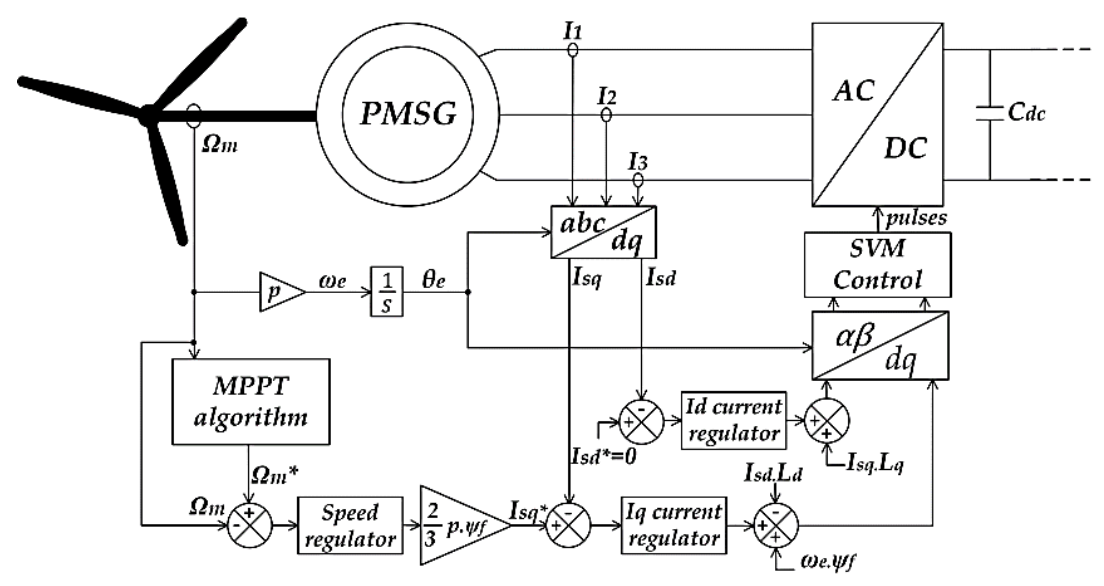

Figure 4. Synoptic diagram of machine side control

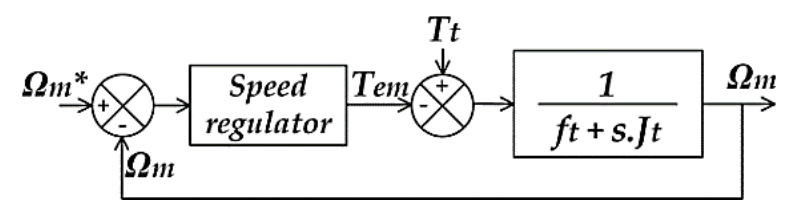

Figure 5. Speed control loop diagram

\subsubsection{Internal currents PI controllers}

As stated in (6), the $\mathrm{d}$-axis and q-axis currents are coupled by the terms $\omega_{e} . L_{q} . I_{s q}, \omega_{e} . L_{d} I_{s d}$ and $\omega_{e} . \psi_{f}$. The block diagram of Figure 6 illustrates the coupling and interaction between the two axes. The coupling terms are considered as internal perturbations. They are generally compensated by the PI regulators in steady state by integrator effect, the integrator reaction is often slow. It is therefore possible to compensate the coupling terms by the decoupling method. Decoupling method involves adding identical terms while opposing the signs at the current correctors output. The decoupling makes the axes $\mathrm{d}$ and q completely independent. This is shown in Figure 6. In the case of "PMSG with smooth rotor", to have a maximum torque and minimum joule losses, it is necessary to set the direct reference current isd* to zero [21]. The torque of the machine will then be directly proportional to the quadrature current isq. The quadrature axis current reference is calculated from the speed controller output.

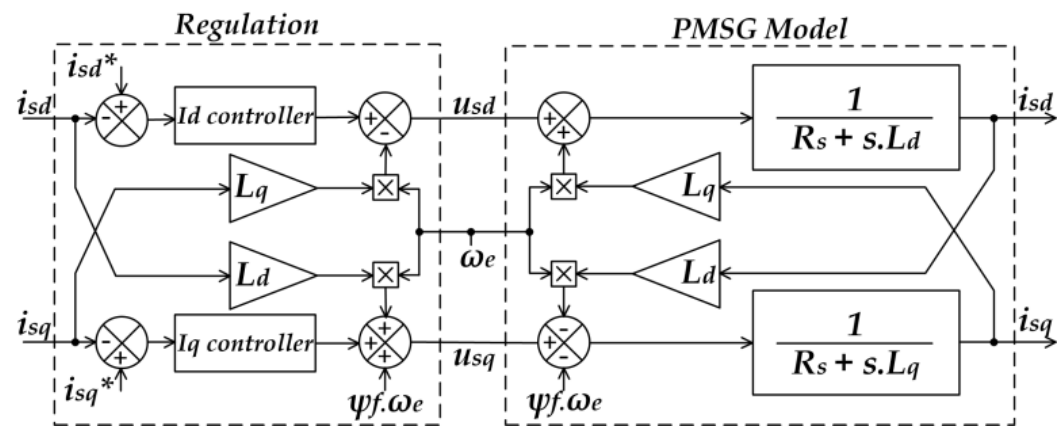

Figure 6. Currents control loop diagram 
The mathematical precision and simplicity algorithm are the PI regulators strengths, but they have some limitations related to the system parameters (resistance, stator inductance, inertia, friction...) [22], these parameters are rarely constant throughout in system operation. The regulators don't always react optimally due to the nonlinear dynamic in the system. Faced with this drawback, a strategy for monitoring the regulator gains by using fuzzy logic is proposed. This technique incorporates a certain intelligence degree in the control strategy. To respect the system control limits, it is recommended to add a saturator at regulator output. However, the use of a saturator can destabilize the system. This is caused by the amplification of noise detection. In fact, this phenomenon causes a decrease in performance [23]. To counter this problem, anti-windup compensation to maintain stability of the closed loop system and minimize deviation from the desired performance is implemented.

\subsubsection{Anti wind-up fuzzy logic controller (AWFLC)}

The control by fuzzy logic with its non-linear structure presents good performance and robustness, but in conventional fuzzy controllers, this non-linearity is incorporated by a limited number of rules generated by human expertise, which may not always be sufficient to produce a necessary control signal [24]. On the other hand, the usual procedure for designing PI controllers is based on a simplified model and with nominal physical parameters. This simplification leads to additional uncertainties on the classic PI controller parameters. The problem can be solved by adapting the controller gains in real time; by using the information provided by the system. In this way, a hybridization technique between the classic PI controller and fuzzy logic it will be done.

Practically, the system has a certain operating limit, due to the stator phase voltages that cannot exceed a given voltage and the maximum torque recommended by the manufacturer, hence the need to add a saturator at the regulators output. The implementation of an integral action on a saturated system causes undesirable effects (significant overtaking, long response time and, sometimes, instability in the response) [25]. When the control signal saturation is activated, it is therefore necessary to limit the integral action. This is achieved by the anti-windup approach. The proposed fuzzy anti-windup PI regulator is shown in Figure 7.

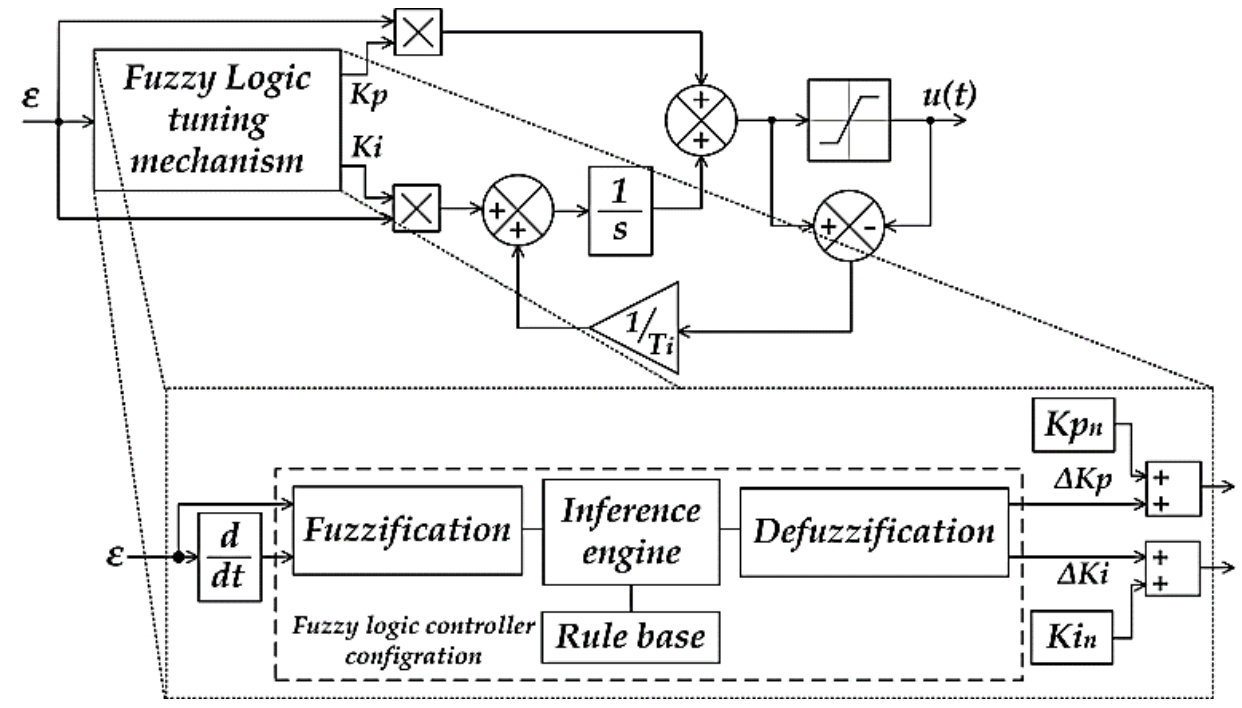

Figure 7. Anti wind-up fuzzy locic controller

The fuzzy logic tuning mechanism role is adjusting on-line the input scaling factors corresponding to the proportional coefficient $\mathrm{Kp}$ and the integral coefficient $\mathrm{Ki}$. Each factor applied to the regulator is composed by the nominal gain and the adaptive gain. The nominal gain is equal to the classic PI gain and the adaptive gain is obtained by fuzzy logic tuning mechanism. Inputs of the fuzzy logic tuning mechanism are the error $\mathrm{E}$ and its derivative $\mathrm{dE}$ at $\mathrm{K}_{\text {th }}$ iteration. $\mathrm{E}$ and $\mathrm{dE}$ are calculated and converted into linguistic variables during fuzzification step as given in Figure 8.

To accomplish the required fuzzy logic operations, a seven-term fuzzy set are defined to describe input variables, positive big (PB), positive medium (PM), positive small (PS), zero (Z), negative small (NS), negative medium (NM) and negative big (NB). Furthermore, an inference is made based on the rules presented in Table 1. These rules are established on the prior knowledge of the system behavior.

Overall fuzzy logic control strategy of direct driven PMSG wind turbine connected to... (Mhamed Fannakh) 

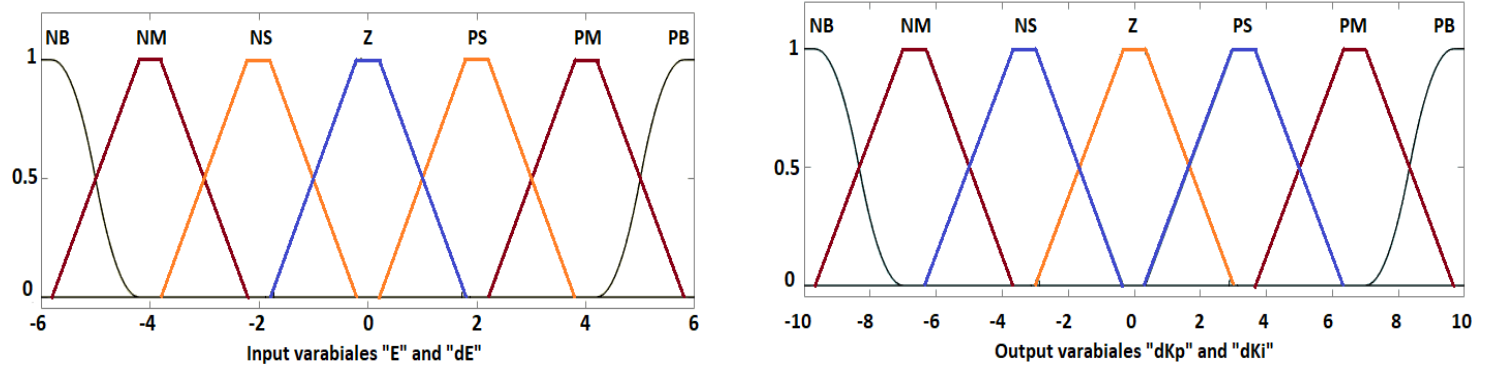

Figure 8. Membership functions of input and output variables

Table 1. Fuzzy rule of proportional term (Kp) and integral term (Ki)

\begin{tabular}{|c|c|c|c|c|c|c|c|c|c|c|c|c|c|c|c|c|c|}
\hline \multirow{2}{*}{\multicolumn{2}{|c|}{ Kp rules }} & \multicolumn{7}{|c|}{$\mathrm{dE}$} & \multirow{2}{*}{\multicolumn{2}{|c|}{ Ki rules }} & \multicolumn{7}{|c|}{$\mathrm{dE}$} \\
\hline & & PB & PM & PS & Z & NS & NM & NB & & & PB & PM & PS & Z & NS & NM & NB \\
\hline $\mathrm{E}$ & PB & PB & PB & PB & $\mathrm{PB}$ & PB & PS & $\mathrm{Z}$ & $\mathrm{E}$ & PB & PB & PB & PB & PB & PB & PS & $\mathrm{Z}$ \\
\hline & PM & PB & PB & PM & PM & PS & Z & Z & & PM & PB & PB & PM & PM & PS & $\mathrm{Z}$ & Z \\
\hline & PS & PM & PS & Z & $\mathrm{Z}$ & Z & NS & NM & & PS & PB & PM & PS & PS & Z & NS & NM \\
\hline & $\mathrm{Z}$ & PS & NS & Z & Z & Z & NS & NM & & Z & NM & NS & Z & Z & Z & NS & NM \\
\hline & NS & NM & NS & Z & Z & Z & PS & PM & & NS & NM & NS & Z & PS & PS & PM & PB \\
\hline & NM & Z & Z & PS & PS & PS & PM & PM & & NM & Z & Z & PS & $\mathrm{PM}$ & PB & PB & $\mathrm{PB}$ \\
\hline & NB & Z & PS & PM & PB & PB & PB & PB & & NB & Z & PS & PM & PB & PB & PB & PB \\
\hline
\end{tabular}

When the fuzzy output is calculated, it must be defuzzified into a numerical value. There are several methods to achieve this transformation. The most used is the center of gravity method, which is adopted in this work. The center gravity abscissa corresponding to the regulator output is given by (14):

$$
\Delta K_{p} / \Delta K_{i}=\frac{\sum_{1}^{49} \mu_{r i} \cdot x_{G i} \cdot S_{i}}{\sum_{1}^{49} \mu_{r i} \cdot S_{i}}
$$

The windup effect introduced by the saturator can be eliminated by applying the "anti-windup compensation" approach. Many anti-windup schemes are discussed in the literature. Jaroslav et al. [26] have concluded that the back calculation method exhibits clear advantages over the other strategies. As mentioned in Figure 7, error between saturated and unsaturated signals is calculated. When the system is unsaturated, the anti-windup system is deactivated. In the other case, i.e .the system is saturated, a feedback signal is activated. The error is multiplied by $1 / \mathrm{T}_{\mathrm{i}}$ gain. Where, Ti is the tracking time constant and which determine the rate at which the integral term is reset.

\subsection{Grid side control strategy}

The grid side control role is to allow a flexible and reliable flow of the maximum extracted power to grid, while ensuring a unit power factor with minimum harmonics pollution. This is assured by the voltage source inverter control. The inverter control is made up of two cascade loops, namely: DC bus voltage regulation loop and grid side currents regulation loop as illustrated in Figure 9.

The DC bus voltage is regulated by adjusting the direct-axis current reference Id*. In classical regulation, the controller synthesis is deducted by "poles placement method". The voltage inverter is controlled by the vector control technique and SVM algorithm. In this strategy, the grid currents are measured and converted into direct-quadrature-zero transformation by using Park matrix. The obtained currents (Id and Iq) are compared with reference values. The direct-axis current reference Id* is deduced from $\mathrm{Vdc}$ regulator and the quadrature-axis current reference is set to zero $\left(\mathrm{Iq}^{*}=0\right)$ to ensure a unit power factor. Two regulators (Id regulator and the Iq regulator) are added to the control structure to minimize the error between the setpoint and the measured value. In the aim of separately controlling the direct $I d$ and quadrature $I q$ currents, the coupling terms $(L \mathrm{n} \omega I q$ and $L \mathrm{n} \omega I d)$ are eliminated by the compensation method described in [17]. The synchronization between the generated signals and that of grid has been accomplished by the phase locked loop (PLL) block, based on a multi-variable filter (MFV) [17]. The block diagram given by Figure 10 summarizes the currents control loops with the decoupling method. To achieve robust regulation, the strategy based on fuzzy logic and anti-windup compensation is also applied in the grid side control. The design of the Mamdani type FLC controller goes through the steps reported previously in section 2.2 . 


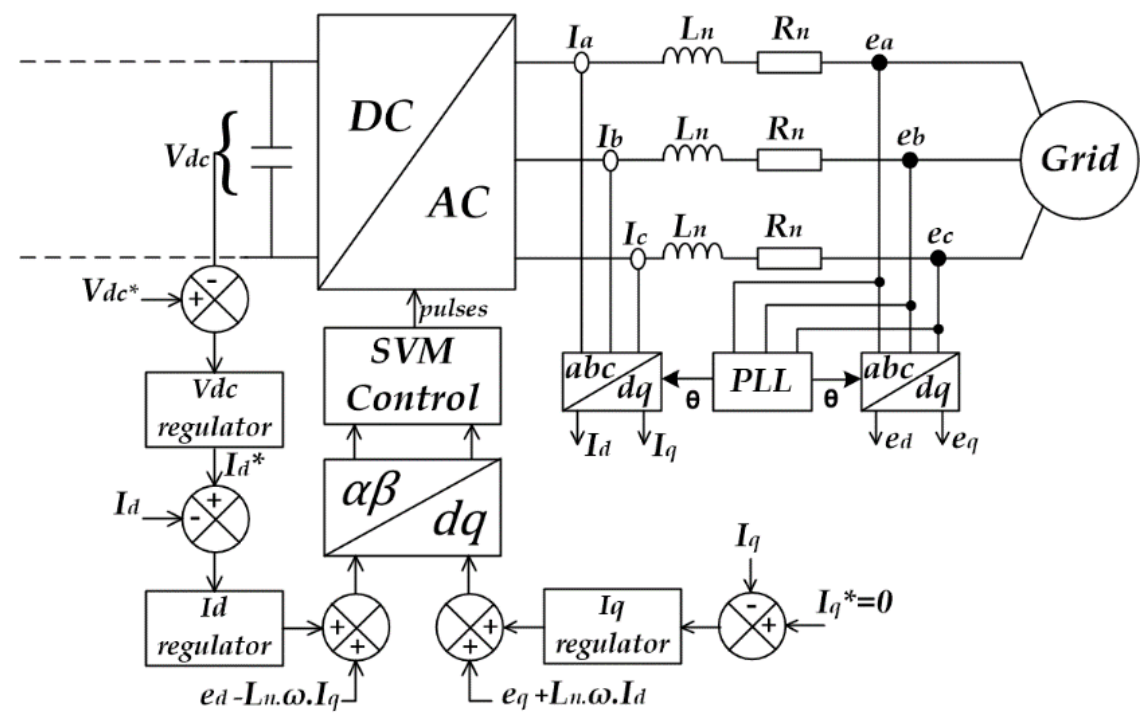

Figure 9. Synoptic diagram of grid side control

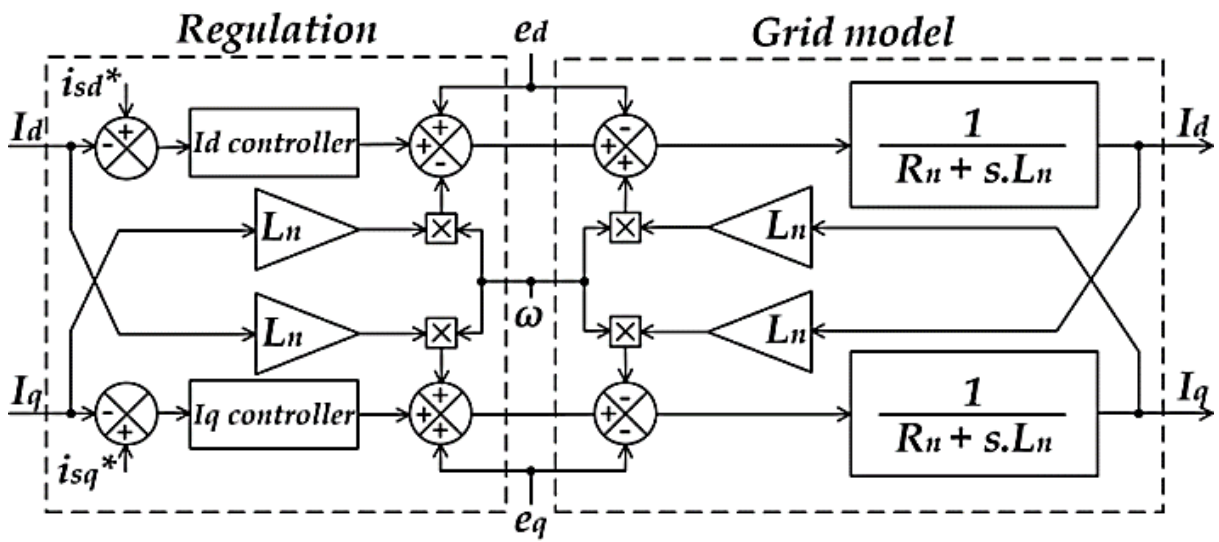

Figure 10. Block diagram the currents control loops

\subsection{Performance test of anti wind-up fuzzy logic controller}

Time-domain test and frequency domain analysis are selected to verify the performance of the proposed controllers. In the following test, the AWFLC is simulated and compared with fuzzy logic selftuning PI controller and classical PI controller. The test concerns speed regulator, the quadrature-axis stator current regulator, DC bus voltage regulator and d-axis grid current regulator. Figure 11 shows the close loop unit step response. Table 2 indicates the optimization results obtained by different regulators on 4 criteria: rise time, settling time, peak and overshoot.

It can be seen from Figure 11 and Table 2 that these regulators can all converge to the final value. The rapidity and precision of the classical PI are poor, where the output fluctuates greatly in transitional regime and the overshoot is higher $(42.92 \%$ in speed regulator). The FLC performances are improved significantly compared with classical PI. In particular, for the overshoot and time response (the settling time has enhanced from $1.300 \mathrm{E}-03 \mathrm{~s}$ to $7.218 \mathrm{E}-04 \mathrm{~s}$ for stator current regulator). Obviously, the tracking time of AWFLC is the shortest for it converges to the final value at $4.518 \mathrm{E}-04 \mathrm{~s}$ in the case of DC bus regulator. The AWFLC seems stable and the oscillations are negligible compared to other techniques.

For stability verification, phase margin criterion via Bode diagram is preceded. Indeed, the criterion proposed in [27], [28] imposes a minimum gain margin of $45^{\circ}$ to consider that the system is stable. The influence of FLC and anti-windup on the system stability is illustrated in Figure 12. It may be observed from Figure 12 that the robustness margin is respected in all techniques. When fuzzy logic is applied, the phase margin has increased considerably. Anti-windup compensation has the effect of attenuating oscillations and recovering system divergence. This is translated by an improvement in the phase margin.

Overall fuzzy logic control strategy of direct driven PMSG wind turbine connected to... (Mhamed Fannakh) 


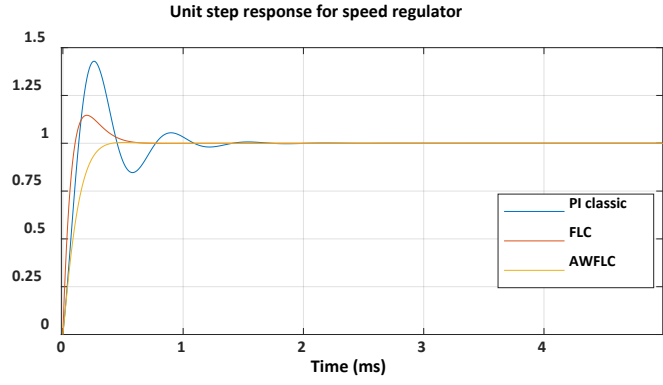

Unit step response for DC voltage regulator

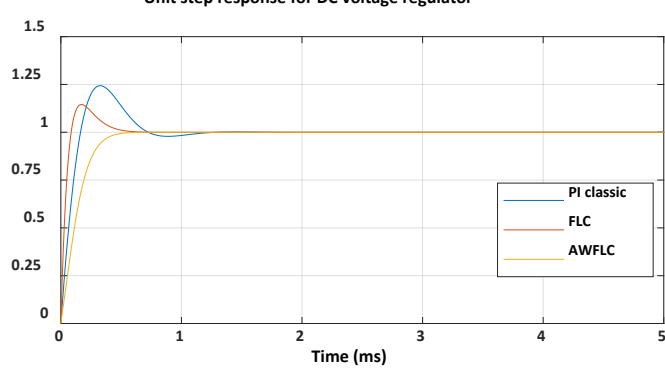

Unit step response for stator current regulato

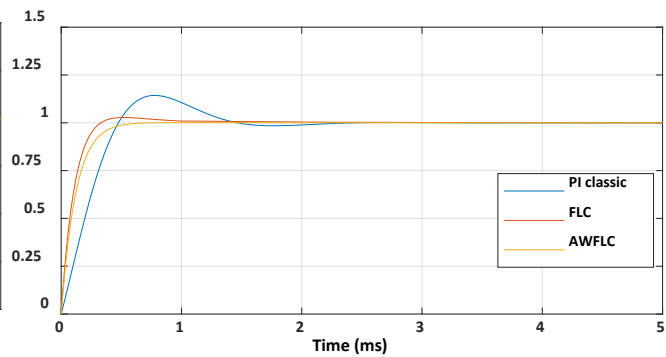

Unit step response for grid current regulator

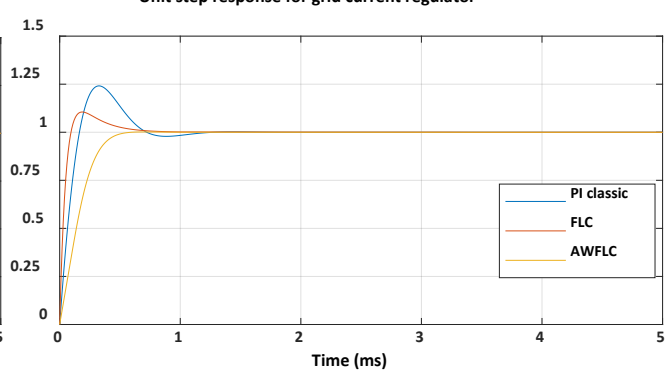

Figure 11. Unit step response for tested controllers

Table 2. Statistical results of step response characteristics

\begin{tabular}{cccccc}
\hline & & Rise time & Settling time & Peak & Overshoot \% \\
\hline Speed & PI & $1.020 \mathrm{E}-04$ & $1.000 \mathrm{E}-03$ & 1.429 & 42.92 \\
regulator & FLC & $7.472 \mathrm{E}-05$ & $4.880 \mathrm{E}-04$ & 1.146 & 14.65 \\
& AWFLC & $2.107 \mathrm{E}-04$ & $3.249 \mathrm{E}-04$ & 1.004 & 0.41 \\
stator current & PI & $3.583 \mathrm{E}-04$ & $1.300 \mathrm{E}-03$ & 1.143 & 14.30 \\
regulator & FLC & $1.993 \mathrm{E}-04$ & $7.218 \mathrm{E}-04$ & 1.028 & 2.75 \\
& AWFLC & $2.614 \mathrm{E}-04$ & $4.528 \mathrm{E}-04$ & 1.000 & 0.08 \\
DC bus & PI & $1.257 \mathrm{E}-04$ & $9.429 \mathrm{E}-04$ & 1.243 & 24.34 \\
regulators & FLC & $6.280 \mathrm{E}-05$ & $4.459 \mathrm{E}-04$ & 1.145 & 14.51 \\
& AWFLC & $2.578 \mathrm{E}-04$ & $4.146 \mathrm{E}-04$ & 1.000 & 0.00 \\
grid current & PI & $1.260 \mathrm{E}-04$ & $9.375 \mathrm{E}-04$ & 1.241 & 24.11 \\
regulators & FLC & $6.599 \mathrm{E}-05$ & $5.494 \mathrm{E}-04$ & 1.105 & 10.53 \\
& AWFLC & $2.951 \mathrm{E}-04$ & $4.518 \mathrm{E}-04$ & 1.002 & 0.16 \\
\hline
\end{tabular}
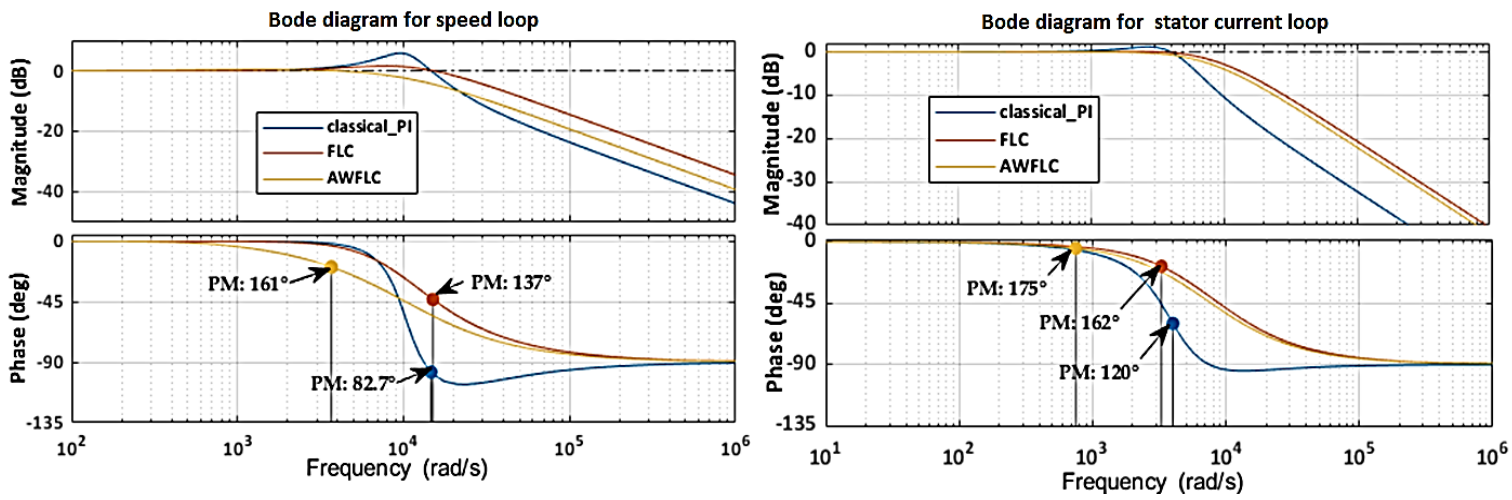

Figure 12. Bode diagram for speed and stator current regulators

\section{RESULTS AND DISCUSSION}

This section will allow to test and compare the performance of different strategies. The system is modeled and simulated in MATLAB/Simulink platform. Energy optimization, DC bus voltage stabilization and total harmonic distortion rate (THD) are evaluated for classical approach and the proposed technique. 
The analysis of the system dynamic behavior is made under wind variations highlighted in Figure 13. All tests are carried out with the same wind profile; the average value of this profile is $9 \mathrm{~m} / \mathrm{s}$.

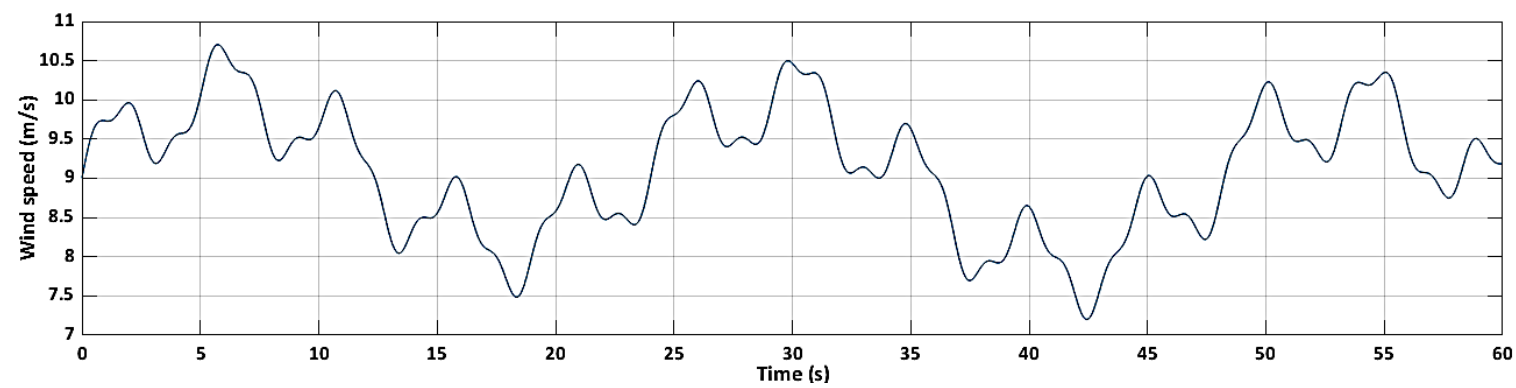

Figure 13. Wind profile

The power coefficient $\mathrm{Cp}$ is shown in Figure 14(a). It is noted that the tested strategies can keep the $\mathrm{Cp}$ at the maximum value (0.48). The observed transient response and the steady state oscillations are not optimal in the case of classical control due to the system inertia, which makes the rotation speed change less rapid than the wind speed variation. The proposed control shows a notable improvement on the transient regime and minimizes significantly the oscillations around the maximum $\mathrm{Cp}$.

In Figure 14(b), the plots of mechanical power produced by the wind turbine using the classical control and the proposed control are presented. There are no significant differences between classical strategy and the proposed strategy in terms of tracking the trajectories imposed by the wind profile. The AWFLC result is significant only in the reduction of oscillations.
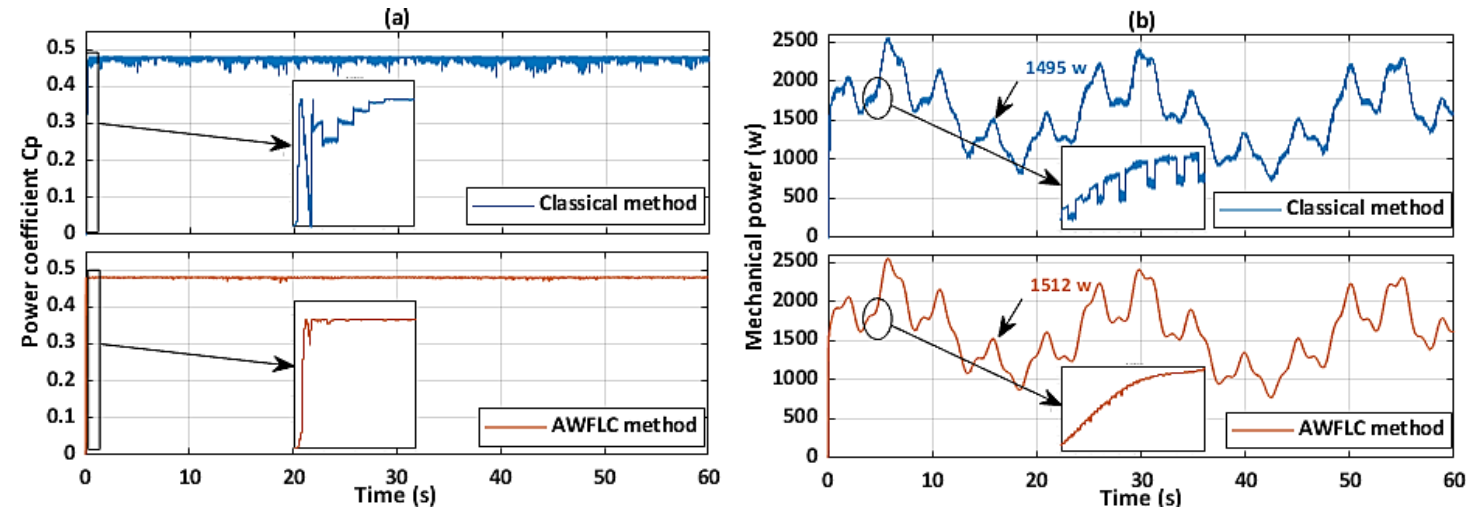

Figure 14. This figure are, (a) power coefficient curve, (b) mechanical power produced by wind turbine

The active and reactive powers injected into grid are presented in Figure 15(a). It can be observed that the electrical power follows the trajectories imposed by the wind profile for both strategies. In the case of suggested strategy, the oscillation is small. On the contrary, the output fluctuates greatly in the other method. According to Figure 15(b), the power factor is kept to 1 after the transient regime, with the advantage of reducing fluctuation when the AWFLC is used. Figure 16 illustrates the DC bus voltage evolution. After a transient regime, it is properly $660 \mathrm{~V}$. It is clarified that the best regulation (faster and less oscillating) is obtained by the AWFLC strategy.

For a $9 \mathrm{~m} / \mathrm{s}$ wind speed, the system efficiency when the proposed strategy is applied is about $91 \%$ while the efficiency is $85 \%$ when the classic strategy is used, which shows more robustness and efficiency. Another criterion for proving the competitiveness of the proposed method is the Total Harmonic Distortion (THD). The THD measures the degree of signal distortion compared to a fundamental sine wave. The IEEE 519-1992 standard indicates that the THD should be less than 5\% for the injected currents [29], [30]. The recorded value of the THD illustrated in Figure 17 is $2.74 \%$ when the control is AWFLC type, while it is $7.93 \%$ when the control is classical type. These results show the advantageous effect of the AWFLC method on the energy quality produced by the PMSG wind turbine.

Overall fuzzy logic control strategy of direct driven PMSG wind turbine connected to... (Mhamed Fannakh) 

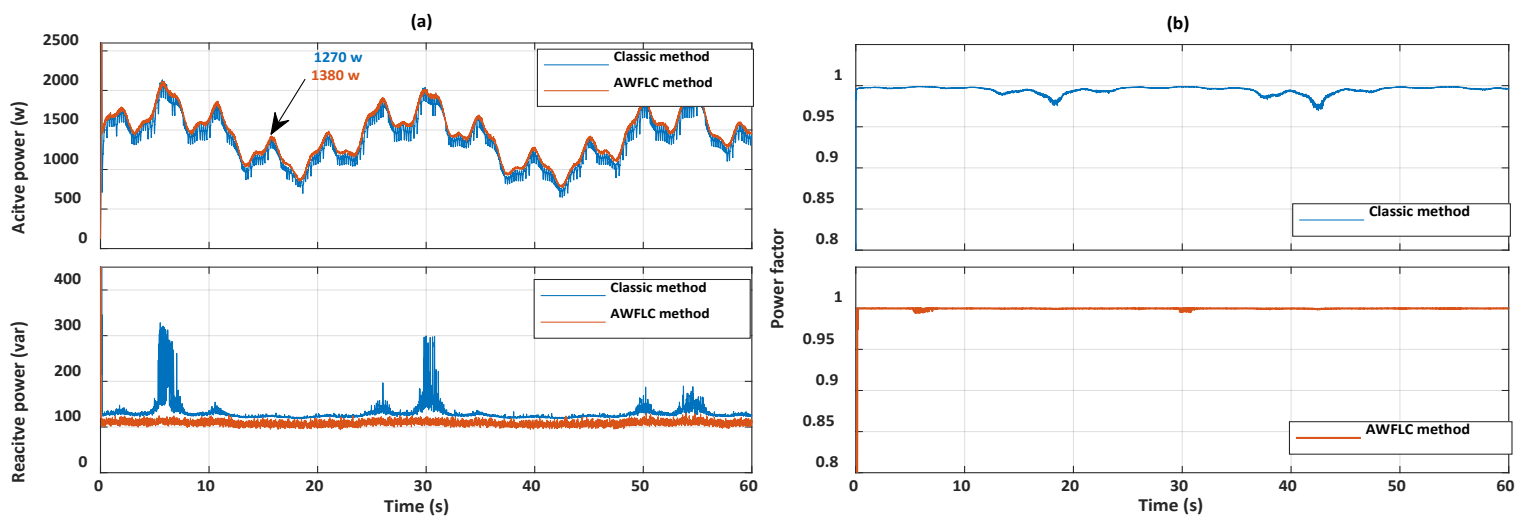

Figure 15. This figure are, (a) active and reactive powers plot, (b) power factor curves

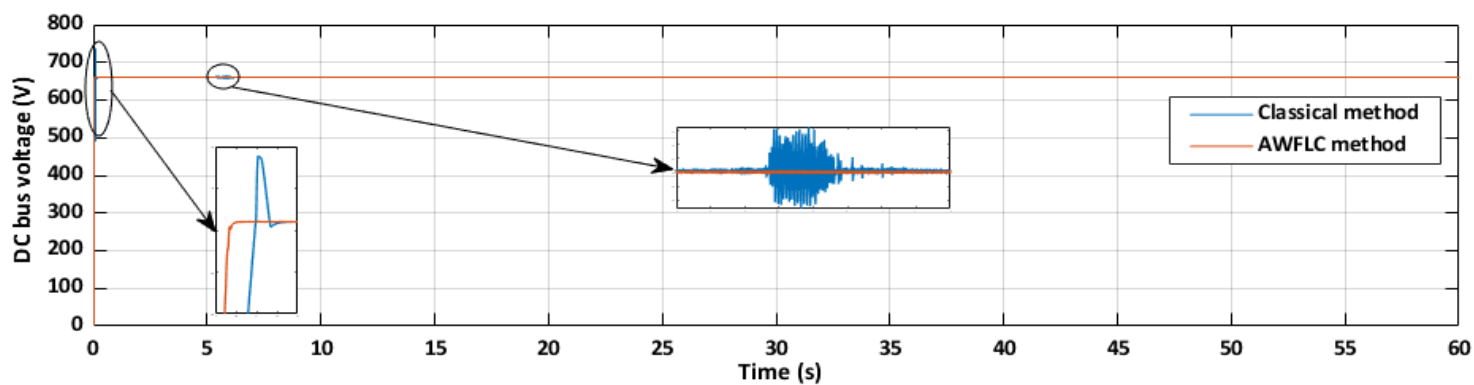

Figure 16. DC bus voltage plot
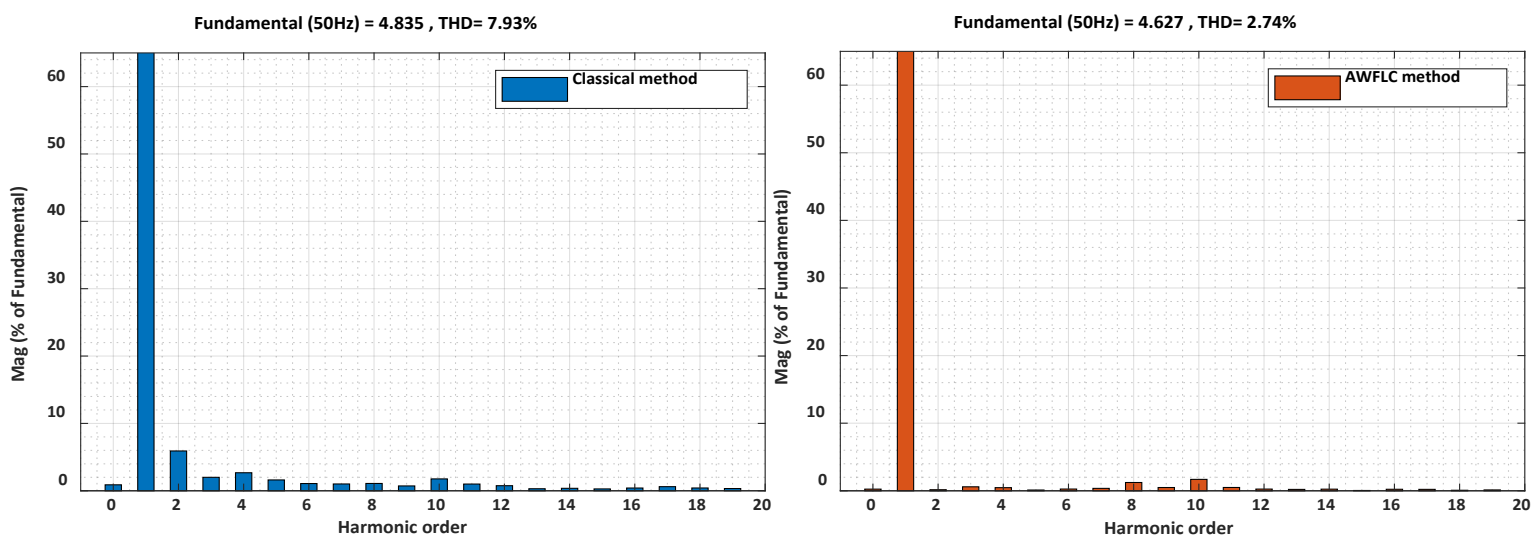

Figure 17. THD analysis

\section{CONCLUSION}

This paper has presented a method based on fuzzy logic control and anti-windup saturation of PMSG wind turbine system connected to grid. Compared with the original HCS, the proposed MPPT employs the fuzzy logic to enhance the search ability of the optimal operating speed, while anti-windup fuzzy logic controllers are used to regulate the rotor speed, the PMSG internal currents, DC bus voltage and grid currents to meeting the requirements of optimization in different stages. Hence, proposed method can search a higher optimum energy quality with a faster speed and a more stable convergence. A simulation series are carried out to verify the effectiveness and advantages of developed strategy compared with other methods. Test results demonstrate that FLC method outperform the other MPPT algorithms, which can not only make the system reach the maximum power quickly and run stably, but also reduce the fluctuation of the output power significantly. Apparently, AWFLC are superior to and classical PI controllers in terms of regulation, 
which verifies that AWFLC is an effective tool for controlling nonlinear systems. Future works include the implementation of these control techniques on the real system and validate their performances through the experimental results.

\section{APPENDIX}

A. WT and PMSG parameters

\begin{tabular}{cc} 
A. WT and PMSG parameters \\
\hline Nominal Power & $1.5 \mathrm{~kW}$ \\
Blade radius & $1.5 \mathrm{~m}$ \\
Air density & 1.225 \\
Pole pairs number & 10 \\
Stator resistance & $1.64 \Omega$ \\
Direct-axis inductance & $0.8 \mathrm{mH}$ \\
Quadrature-axis inductance & $0.8 \mathrm{mH}$ \\
Flux linkage & $0.175 \mathrm{~Wb}$ \\
Moment of inertia & $1.469 \mathrm{E}^{-3} \mathrm{~kg} \cdot \mathrm{m}^{2}$ \\
Static friction & $0.3035 \mathrm{E}^{-3} \mathrm{~N} \cdot \mathrm{m} . \mathrm{s}$ \\
\hline
\end{tabular}

\begin{tabular}{ccc}
\multicolumn{3}{c}{ B. The PI regulator gains } \\
\hline Speed & $\mathrm{Kp}$ & 5.87 \\
regulator & $\mathrm{Ki}$ & 411.3 \\
stator current & $\mathrm{Kp}$ & 3 \\
regulator & $\mathrm{Ki}$ & 7650.6 \\
DC bus & $\mathrm{Kp}$ & 13.2 \\
regulators & $\mathrm{Ki}$ & 924 \\
grid current & $\mathrm{Kp}$ & 19.8 \\
regulators & $\mathrm{Ki}$ & 11754.2 \\
\hline
\end{tabular}

\section{REFERENCES}

[1] T. Kousksou et al., "Renewable energy potential and national policy directions for sustainable development in Morocco," Renew. Sustain. Energy Rev., vol. 47, pp. 46-57, 2015, doi: 10.1016/j.rser.2015.02.056.

[2] S. Benzaouia, Z. Smail, R. Abdelhamid, M. L. Elhafyani, M. Mohammed, and F. Mhamed, "A comparative investigation and evaluation of maximum power point tracking algorithms applied to wind electric water pumping system," International Conference on Electronic Engineering and Renewable Energy, pp. 510-523, 2018, doi: 10.1007/978-981-13-1405-6_60.

[3] K. Rabyi and H. Mahmoudi, "Energy storage of DFIG based wind farm using D-STATCOM," International Journal of Electrical and Computer Engineering (IJECE), vol. 9, no. 2, pp. 761-770, 2019, doi: 10.11591/ijece.v9i2.pp761-770.

[4] J. N. and Sachin, "Study of grid connected wind energy system with fuzzy logic based MPPT controller," IAES International Journal of Robotics and Automation (IJRA), vol. 7, no. 4, pp. 251-261, 2018, doi: 10.11591/ijra.v7i4.pp251-261.

[5] Q. Zhou, H. Li, C. Wu, L. Wang, and C. K. Ahn, "Adaptive fuzzy control of nonlinear systems with unmodeled dynamics and input saturation using small-gain approach," IEEE Trans. Syst. Man Cybern. Syst., vol. 47, no. 8, pp. 1979-1989, 2017, doi: 10.1109/TSMC.2016.2586108.

[6] N. A. Sofianos, and Y. S. Boutalis, "Stable indirect adaptive switching control for fuzzy dynamical systems based on T-S multiple models," Int. J. Syst. Sci., vol. 44, no. 8, pp. 1546-1565, 2013, doi: 10.1080/00207721.2012.659697.

[7] N. A. Sofianos and Y. S. Boutalis, "Robust adaptive multiple models based fuzzy control of nonlinear systems," Neurocomputing, vol. 173, pp. 1733-1742, 2016, doi: 10.1016/j.neucom.2015.09.047.

[8] X. P. Li, W. L. Fu, Q. J. Shi, J. B. Xu, and Q. Y. Jiang., “A fuzzy logical MPPT control strategy for PMSG wind generation systems," Journal of Electronic Science and Technology, vol. 11, no. 1, pp. 72-77, 2013, doi: 10.3969/j.issn.1674-862X.2013.01.013.

[9] A. G. Aissaoui, A. Tahour, N. Essounbouli, F. Nollet, M. Abid, and M. I. Chergui, "A Fuzzy-PI control to extract an optimal power from wind turbine," Energy Convers. Manag., vol. 65, pp. 688-696, 2013, doi: 10.1016/j.enconman.2011.11.034.

[10] J. Zaragoza, C. S. Staines, A. Arias, J. Pou, E. Robles, and S. Ceballos, "Comparison of speed control strategies for maximum power tracking in a wind energy conversion system," in Melecon 2010 - 2010 15th IEEE Mediterranean Electrotechnical Conference, 2010, pp. 961-966, doi: 10.1109/MELCON.2010.5475919.

[11] M. Mansour, M. N. Mansouri, S. Bendoukha, and M. F. Mimouni, "A grid-connected variable-speed wind generator driving a fuzzy-controlled PMSG and associated to a flywheel energy storage system," Electric Power Syst. Res., vol. 180, pp. 106137, 2020, Art. no. 106137, doi: 10.1016/j.epsr.2019.106137.

[12] A. M. Howlader N Urasaki, A Pratap, T Senjyu, and A. Y. Saber, "A fuzzy control strategy for power smoothing and grid dynamic response enrichment of a grid-connected wind energy conversion system: Fuzzy control strategy for power smoothing and grid control," Wind Energy, vol. 17, no. 9, pp. 1347-1363, 2013, doi: 10.1002/we.1637.

Overall fuzzy logic control strategy of direct driven PMSG wind turbine connected to... (Mhamed Fannakh) 
[13] R. Bontempo and M. Manna, "Effects of the approximations embodied in the momentum theory as applied to the NREL PHASE VI wind turbine," Int. J. Turbomach. Propuls. Power, vol. 2, no. 2, 2017, Art. no. 9, doi: 10.3390/ijtpp2020009.

[14] R. Melcio, V. M. F. Mendes, and J. P. S. Catalão, "Wind turbines with permanent magnet synchronous generator and full-power converters: Modelling, control and simulation," Wind Turbines IntechOpen, pp. 465-470, 2011, doi: $10.5772 / 14597$.

[15] A. Rahab, H. Benalla, and F. Senani, "Improved virtual flux direct power control of three phase PWM rectifier using SOGI-FLL estimator under disturbed voltage conditions," International Journal of Applied Power Engineering (IJAPE), vol. 8, no. 1, pp. 34-42, 2019, doi: 10.11591/ijape.v8.i1.pp34-42.

[16] A. António-Ferreira, C. Collados-Rodriguez, and O. Gomis-Bellmunt, "Modulation techniques applied to medium voltage modular multilevel converters for renewable energy integration: A review," Electric Power Syst. Res., vol. 155, pp. 21-39, 2018, doi: 10.1016/j.epsr.2017.08.015.

[17] M. Fannakh, M. L. Elhafyani, S. Zouggar, M. Mokhtari, and S. Benzaouia., "A decoupled control study of a gridconnected photovoltaic power system," International Conference on Electronic Engineering and Renewable Energy, 2018, pp. 565-575, doi: 10.1007/978-981-13-1405-6_65.

[18] P. Gajewski, "Stand-alone wind energy conversion system with pmsg and energy storage," Maszyny Elektryczne: zeszyty problemowe, vol. 1, no. 113, pp. 141-146, 2017, doi: 0239-3646.

[19] L. A. Zadeh, "Fuzzy sets, fuzzy logic, and fuzzy systems," World Scientific Publishing Company, 1996, doi: $10.1142 / 2895$.

[20] M. Fannakh, M. Larbi Elhafyani, S. Zouggar, and H. Zahboune., "Performances MPPT enhancement in PMSG wind turbine system using fuzzy logic control," International Conference on Electronic Engineering and Renewable Energy, 2020, pp. 797-807, doi: 10.1007/978-981-15-6259-4_84.

[21] D. Yadav and A. Verma, "Comperative Performance Analysis of PMSM Drive Using MPSO and ACO Techniques," Int. J. Power Electron. Drive Syst. (IJPEDS), vol. 9, no. 4, pp. 1510-1522, 2018, doi: 10.11591/ijpeds.v9.i4.pp1510-1522.

[22] M. A. Hannan et al., "Quantum-behaved lightning search algorithm to improve indirect field-oriented fuzzy-PI control for IM drive," IEEE Trans. Ind. Appl., vol. 54, no. 4, pp. 3793-3805, 2018, doi: 10.1109/TIA.2018.2821644

[23] P. Kheirkhahan, "Robust anti-windup control design for PID controllers," 17th International Conference on Control, Automation and Systems (ICCAS), 2017, pp. 1622-1627, doi: 10.23919/ICCAS.2017.8204247.

[24] I. A. Ozkan, S. Herdem, and I. Saritas, "FPGA-based self-organizing fuzzy controller for electromagnetic filter," Neural Comput. Appl., vol. 28, no. 9, pp. 2535-2543, 2017, doi: 10.1007/s00521-016-2199-6.

[25] L. Angel, J. Viola, and M. Paez., "Evaluation of the windup effect in a practical PID controller for the speed control of a DC-motor system," 2019 IEEE 4th Colombian Conference on Automatic Control (CCAC), 2019, pp. 1-6, doi: 10.1109/CCAC.2019.8921219.

[26] J. Busek, T. Vyhlídal, and P. Zítek., "IAE based tuning of controller anti-windup schemes for first order plus deadtime system," 2017 21st International Conference on Process Control (PC) IEEE, 2017, pp. 18-23, doi: 10.1109/PC.2017.7976182.

[27] J. W. M. Bergmans, "Effect of loop delay on phase margin of first-order and second-order control loops," IEEE Trans. Circuits Syst. II Analog Digit. Signal Process., vol. 52, no. 10, pp. 621-625, 2005, doi: 10.1109/TCSII.2005.852003.

[28] N. R. Kudithi and S. Somkun, "Power flow management of triple active bridge for fuel cell applications," International Journal of Power Electronics and Drive Systems (IJPEDS), vol. 10, no. 2, pp. 672-681, 2019, doi: 10.11591/ijpeds.v10.i2.672-681.

[29] M. McGranaghan, "Overview of the guide for applying harmonic limits on power systems-IEEE P519A," 8th International Conference on Harmonics and Quality of Power. Proceedings (Cat. No.98EX227), 2002, pp. 462-469, doi: 10.1109/ICHQP.1998.759953.

[30] M. Fannakh, M. L. Elhafyani, and S. Zouggar, "Fuzzy logic approach to improve the performances of gridconnected photovoltaic power system," 2018 6th International Renewable and Sustainable Energy Conference (IRSEC), 2018, pp. 1-6, doi: 10.1109/IRSEC.2018.8703028.

\section{BIOGRAPHIES OF AUTHORS}

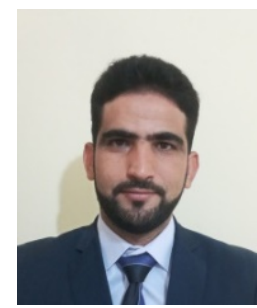

Mhamed Fannakh was born in Guercif, Morocco on March 2, 1989. He received the Technical University Degree in electrical engineering and power electronics from the High School of Technology, Oujda, Morocco, and Engineering degree in electrical engineering from the National School of Applied Sciences Oujda, Morocco, in 2010 and 2013, respectively. He is currently a $\mathrm{PhD}$ student in Laboratory of Electrical Engineering and Maintenance - LEEM, University Mohammed 1st, High School of Technology, Oujda, Morocco. His research interests include photovoltaic energy, wind energy and energy management in hybrids systems. 


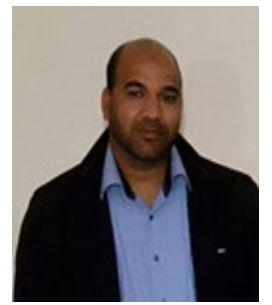

Mohamed Larbi Elhafyani is Professor at Mohamed first university, Oujda, Morocco and currently member at Electrical Engineering and Maintenance Laboratory (LGEM). He received with Honors the Ph.D degree in electrical machines \& power electronic (renewable energy), from faculty of science, university Mohamed first, Oujda in 2008. His current area of interest is related to the advanced control of wind turbine system, power electric and renewable energy.

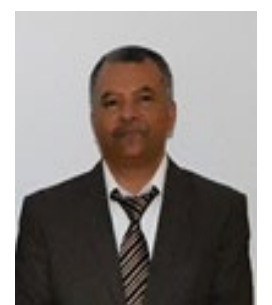

Smail Zouggar is currently full Professor at High School of Technology, Mohamed I University, Oujda, Morocco where he was until 2019 head of the Electrical Engineering and Maintenance Laboratory (LGEM). He received Master's degree in Electrical Engineering from Hassania School of Public Works (EHTP), Casablanca, Morocco in 1989. In 2001 he received $\mathrm{PhD}$ degree in Power Electronics, from Faculty of Science, Mohamed I University. His current research topics include theory, design, modelling and characterization of hybrid system combining wind and photovoltaic system.

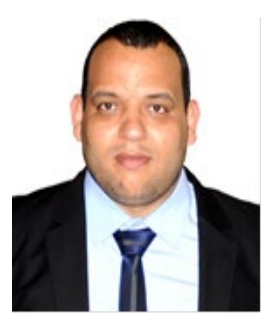

Hassan Zahboune is an Assistant Professor, Department of electrical Engineering, from the High School of Technology (HST), university Mohamed first, Oujda, Morocco, and member at Laboratory of Electrical Engineering and Maintenance (LEEM). Engineering degree in electrical engineering from the National School of Applied Sciences (NSAS) Oujda, Morocco, in 2011. He received with Honors the Ph.D. degree in electrical engineering \& renewable energies, from the HST, Oujda in 2017. His research interest includes Renewable Energy, Energy Management, Power System Analysis and Electrical Installation. 